\title{
Respiratory Muscle Training in Patients With Moderate to Severe Myasthenia Gravis
}

\author{
Paltiel Weiner, Ditza Gross, Zeev Meiner, Rushrash Ganem, Margalit Weiner, \\ Doron Zamir and Marinella Rabner
}

\begin{abstract}
Background: Myasthenia gravis (MG) is a specific autoimmune disease characterized by weakness and fatigue. MG may affect also the respiratory muscles causing symptoms that may vary from dyspnea on severe exertion to dyspnea at rest. This study was undertaken in order to determine the effects of respiratory muscle training on respiratory muscle performance, spirometry data and the grade of dyspnea in patients with moderate to severe generalized MG. Methods: Eighteen patients with MG were studied and divided into 2 groups: Group A included 10 patients ( 3 males and 7 females aged 29-68) with moderate MG, and Group B that included 8 patients (5 males and 3 females aged 21-74) with severe MG. Patients in Group A received both inspiratory and expiratory muscle training for 1/2 h/day, 6 times a week, for 3 months, while patients in Group B followed the same protocol but had inspiratory muscle training only. Results: Mean $\mathrm{PI}_{\max }$ increased significantly from $56.6 \pm 3.9$ to $87.0 \pm 5.8 \mathrm{~cm} \mathrm{H}_{2} \mathrm{O}$ (p $<0.001$ ) in Group A, and from $28.9 \pm 5.9$ to $45.5 \pm$ $6.7 \mathrm{~cm} \mathrm{H} \mathrm{H}_{2} \mathrm{O}(\mathrm{p}<0.005)$ in Group B. The mean $\mathrm{PE}_{\max }$ also increased significantly in patients in Group A, but remained unchanged in the patients in Group B. The respiratory muscle endurance also increased significantly, from $47.9 \pm 4.0$ to $72.0 \pm 4.2 \%$, $p<0.001$, in patients of Group A, and from $26.0 \pm 2.9$ to $43.4 \pm 3.8, \mathrm{p}<0.001$, in patients in Group B. The improved respiratory muscle performance was associated with a significant increase in the FEV, values, and in the FVC values, in patients of both groups. Mean dyspnea index score also increased significantly from $2.6 \pm 0.8$ to $3.6 \pm 0.4(\mathrm{p}<0.005)$ in Group $\mathrm{A}$, and from $0.7 \pm 0.2$ to $2.0 \pm 0.2$ (p $<0.001$ ) in Group $\mathrm{B}$. Conclusions: Specific inspiratory threshold loading training alone, or combined with specific expiratory training, markedly improved respiratory muscle strength and endurance in patients with MG. This improvement in respiratory muscle performance was associated with improved lung function and decreased dyspnea. Respiratory muscle training may prove useful as a complementary therapy with the aim of reducing dyspnea symptoms, delay the breathing crisis and the need for mechanical ventilation in patients with MG.
\end{abstract}

RÉSUMÉ: Entraînement des muscles respiratoires chez les patients porteurs d'une myasthénie grave modérée à sévère. Introduction: La myasthénie grave (MG) est une maladie autoimmune caractérisée par de la faiblesse et de la fatigue. La MG peut atteindre également les muscles respiratoires causant des symptômes allant de la dyspnée à l'exercice intense à la dyspnée au repos. Le but de cette étude était de déterminer les effets de l'entraînement des muscles respiratoires sur la performance des muscles respiratoires, les données de la spirométrie et le grade de la dyspnée chez les patients ayant une MG généralisée de modérée à sévère. Méthodes: Dix-huit patients souffrant de MG ont été étudiés et divisés en 2 groupes: le groupe A comprenait 10 patients ( 3 hommes et 7 femmes âgés de 29 à 68 ans) ayant une MG modérée et le groupe B comprenait 8 patients (5 hommes et 3 femmes âgés de 21 à 74 ans) ayant une MG sévère. Les patients du groupe A ont reçu un entraînement des muscles pour l'inspiration et l'expiration pendant 1/2 heure par jour, 6 jours par semaine, pendant 3 mois, et les patients du groupe B ont suivi le même protocole, mais sans entraînement des muscles expiratoires. Résultats: Le $\mathrm{PI}_{\max }$ augmentait significativement de $56 . \pm 63.9$ à $87.0 \pm 5.8 \mathrm{~cm} \mathrm{H}_{2} \mathrm{O}(\mathrm{p}<0.001)$ dans le groupe A et de $28.9 \pm 5.9$ à $45.5 \pm$ $6.7 \mathrm{~cm} \mathrm{H} \mathrm{H}_{2} \mathrm{O}(\mathrm{p}<0.005)$ dans le groupe $\mathrm{B}$. Le $\mathrm{PE}_{\max }$ avait également augmenté de façon significative chez les patients du groupe A, mais était demeuré inchangé chez les patients du groupe B. L'endurance des muscles respiratoires avait également augmenté de façon significative, de $47.9 \pm 4.0$ à $72.0 \pm$ $4.2 \%, \mathrm{p}<0.001$, chez les patients du groupe $\mathrm{A}$ et de $26.0 \pm 2.9$ à $43.4 \pm 3.8, \mathrm{p}<0.001$, chez les patients du groupe B. L'amélioration de la performance des muscles respiratoires était associée à une augmentation significative dans les valeurs du VEMS et dans les valeurs de CVF chez les patients des deux groupes. Le score à l'indice de dyspnée était également augmenté de façon significative de $2.6 \pm 0.8$ à $3.6 \pm 0.4(\mathrm{p}<0.005)$ dans le groupe A et de $0.7 \pm$ 0.2 à $2.0 \pm 0.2(\mathrm{p}<0.001)$ dans le groupe B. Conclusions: L'entraînement à un seuil de charge inspiratoire spécifique seul ou combiné à l'entraînement expiratoire spécifique améliore de façon marquée la force des muscles respiratoires et l'endurance des patients atteints de MG. Cette amélioration dans la performance des muscles respiratoires était associée à une amélioration de la fonction pulmonaire et à une diminution de la dyspnée. L'entraînement des muscles respiratoires peut être un traitement complémentaire dont le but est de diminuer les symptômes de dyspnée, de retarder la crise respiratoire et le recours à la ventilation mécanique chez les patients atteints de MG.

Can. J. Neurol. Sci. 1998; 25: 236-241

Myasthenia gravis (MG) is an acquired disorder of the neuromuscular junction caused by antibodies directed against the acetylcholine receptors, ${ }^{1 \cdot 3}$ and characterized by skeletal muscle weakness and fatigue. ${ }^{4}$ MG may affect both inspiratory and expiratory muscles ${ }^{5}$ and usually both the inspiratory and the expiratory muscles are affected to the same degree. ${ }^{6}$ Symptoms
From the Department of Medicine A, Hillel Yaffe Medical Center, Hadera (P.W.. R.G. M.W., D.Z., M.R.), the Departments of Anesthesia (D.G.), and Neurology (Z.M.), Hadassah University Hospital, Jerusalem, Israel.

RECEIVED MAY 15, 1997. ACCEPTED IN FINAL FORM JANUARY 14, 1998.

Reprint requests to: Paltiel Weiner, Department of Medicine A, Hillel-Yaffe Medical Center, Hadera, Israel 38100 
due to respiratory muscle involvement depend on the severity of the disease, and may vary from dyspnea on mild to moderate exertion to respiratory failure that require prolonged periods of assisted ventilation. ${ }^{7-9}$ Anticholinesterase therapy, thymectomy and immunosupression are frequently used in the treatment of MG. ${ }^{1,10,11}$ However, only a few patients will regain normal function with the therapy.12

It is well established that respiratory muscles can be trained for both strength and endurance like other skeletal muscles and several reviews have been published dealing with ventilatory muscle training. ${ }^{13.15}$ Its efficacy has been previously shown in normal subjects, ${ }^{16}$ quadriplegics, ${ }^{17}$ cystic fibrosis, asthma, ${ }^{18}$ patients on chronic hemodialysis, ${ }^{19}$ patients undergoing open heart surgery ${ }^{20.21}$ as well as in patients with COPD. ${ }^{22}$ However, our research revealed only one study, with a small group of patients, in which the respiratory muscles were trained specifically in patients with $M \mathrm{MG}^{23}$

This study was designed in order to assess the effects of respiratory muscle training (RMT) on inspiratory and expiratory muscle strength, endurance, lung function, and dyspnea, in a population of adult MG patients.

\section{Methods}

Patients Eighteen patients with MG (10 women and 8 men) 21 to $74 \mathrm{yr}$ age (mean $\pm \mathrm{SEM}, 45.4 \pm 3.7 \mathrm{yr}$ ) were included in the study. The diagnosis of MG was based on a history of fatiga- ble muscle weakness, by a decremental response of the amplitude of the motor response to repetitive nerve stimulation and by a positive edrophonium test. ${ }^{4}$ Acetylcholine receptor antibodies were investigated in 14 patients, and were present in 12. All had some degree of dyspnea, and were classified functionally according to the Osserman grade ${ }^{24}$ (Table 1). The patients were divided into 2 groups: 10 patients that were mildly and moderately affected (of Osserman classifiction II and III) (Group A) and received both inspiratory muscle and expiratory muscle training, and 8 patients with severe MG (Osserman classification IV) (Group B) received inspiratory muscle training only. All patients were treated by anticholinesterase, 13 had thymectomy, and 11 received steroids (prednisone $20-40 \mathrm{mg}$ on alternate days). No change in drug therapy was allowed during the study. Two patients, in Group B (No. 1, 2) were treated with supplemental oxygen before training.

Spirometry Pulmonary functions were assessed by spirometry, performed before, 1 month and 3 months following RMT. The forced vital capacity (FVC) and the forced expiratory volume in one second $\left(\mathrm{FEV}_{1}\right)$ were measured 3 times on a computerized spirometer (Compact, Vitalograph, Buckingham England) and the best trial is reported.

Respiratory muscle strength Respiratory muscle strength was assessed by measuring the maximal inspiratory mouth pressure $\left(\mathrm{PI}_{\max }\right)$ at residual volume (RV) and the maximal expiratory mouth pressure $\left(\mathrm{PE}_{\max }\right)$ at total lung capacity (TLC) as previously described by Black and Hyatt. ${ }^{25}$ The value obtained from the

Table 1: Characteristics of Patients With Myasthenia Gravis.

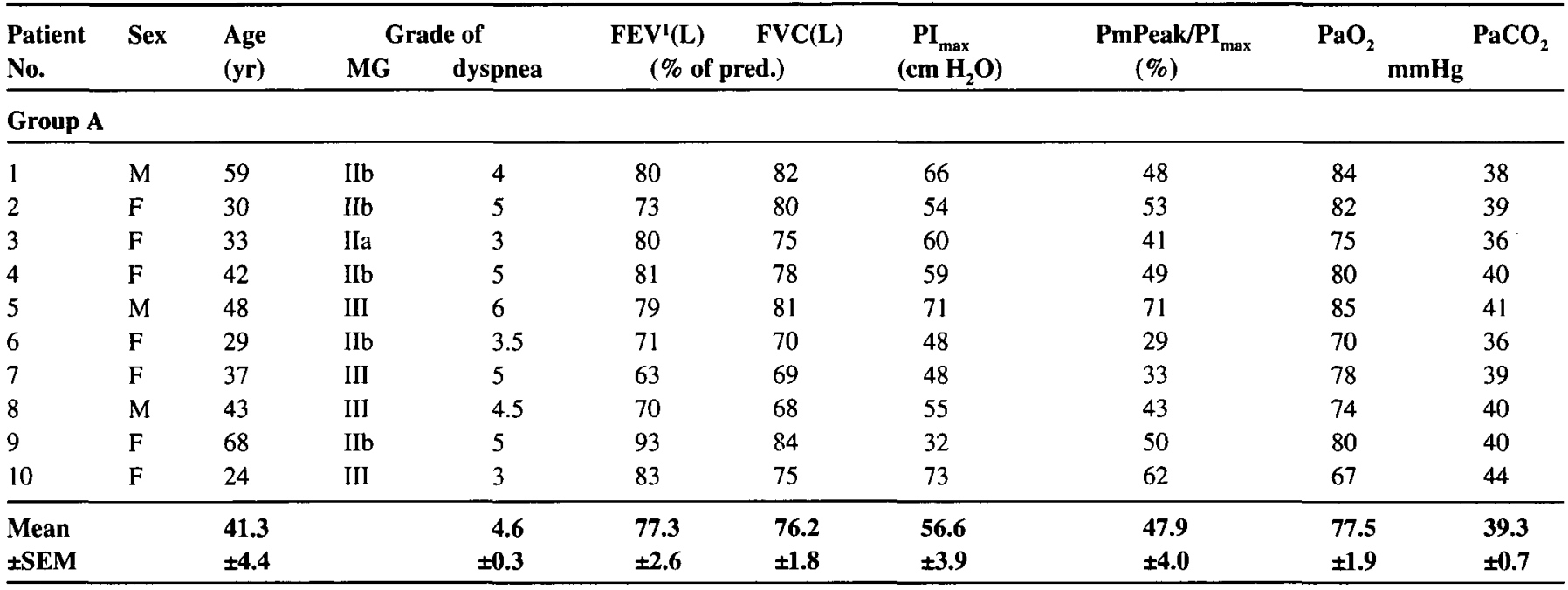

\section{Group B}

\begin{tabular}{|c|c|c|c|c|c|c|c|c|c|c|}
\hline 1 & $\mathrm{M}$ & 74 & IV & 0 & 10 & 14 & 7 & 12 & 51 & 65 \\
\hline 2 & $\mathrm{~F}$ & 43 & IV & 0 & 13 & 22 & 10 & 5 & 48 & 80 \\
\hline 3 & $\mathbf{F}$ & 66 & IV & 1 & 8 & 26 & 15 & 8 & 65 & 47 \\
\hline 4 & $\mathrm{M}$ & 50 & IV & 0.5 & 27 & 27 & 5 & 16 & 60 & 48 \\
\hline 5 & $\mathbf{M}$ & 65 & IV & 1 & 47 & 39 & 40 & 56 & 75 & 45 \\
\hline 6 & $\mathbf{M}$ & 21 & IV & 1 & 49 & 44 & 41 & 32 & 78 & 61 \\
\hline 7 & $F$ & 42 & IV & 1 & 35 & 51 & 23 & 53 & 68 & 41 \\
\hline 8 & $\mathbf{M}$ & 43 & IV & 1 & 41 & 60 & 33 & 26 & 65 & 55 \\
\hline Mean & & 50.5 & & 0.7 & 28.9 & 35.4 & 21.7 & 26.9 & 63.8 & 55.3 \\
\hline \pm SEM & & \pm 6.1 & & \pm 0.2 & \pm 5.9 & \pm 5.6 & \pm 5.2 & \pm 7.0 & \pm 3.7 & \pm 4.6 \\
\hline
\end{tabular}




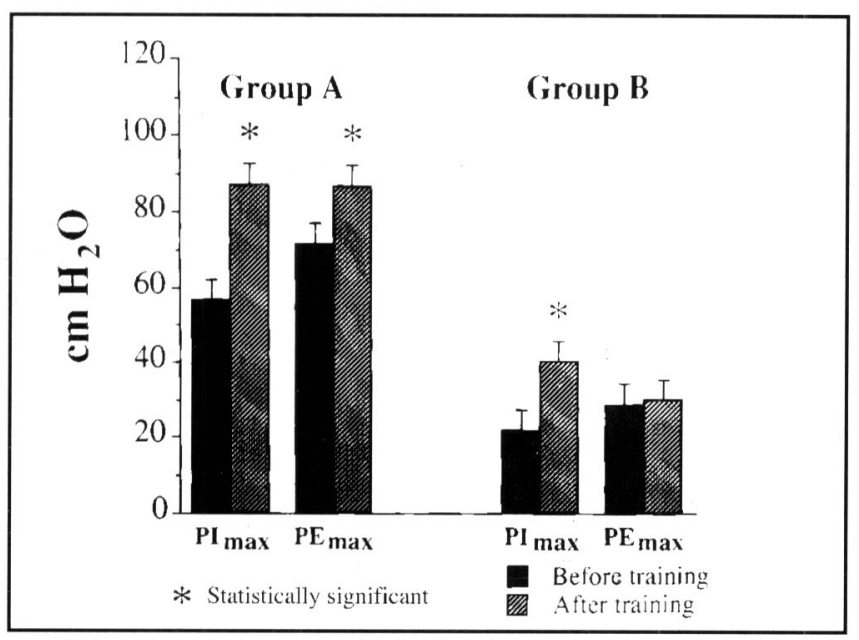

Figure 1: Inspiratory muscle strength, as expressed by the $P I_{\max }$ at $R V$, and the expiratory muscle strength, as expressed by the $P E_{\max }$ at $T L C$, at baseline, and after 3 months of training, in patients with moderate (Group A) and severe (Group B) myasthenia gravis.

best of at least 3 efforts was used.

Dynamic inspiratory muscle strength Dynamic inspiratory muscle strength was assessed by measuring the maximal inspiratory mouth pressure $\left(\mathrm{PI}_{\max }\right)$ at residual volume (RV) every 30 seconds and up to 6 measurements.

Inspiratory muscle endurance To determine inspiratory muscle endurance a device similar to that proposed by Nickerson and Keens ${ }^{26}$ was used. Subjects inspired through a two-way Hans-Rudolph valve whose inspiratory port was connected to a chamber and plunger to which weights could be added externally. Inspiratory elastic work was then increased by the progressive addition of 25 to $100 \mathrm{~g}$ weights at 2-min intervals, as was previously described by Martyn and coworkers, ${ }^{27}$ until the subjects were exhausted and could no longer inspire. The pressure achieved with the heaviest load (tolerated for at least $60 \mathrm{~s}$ ) was defined as the peak pressure $\left(\mathrm{P}_{\mathrm{m}}\right.$ Peak).

Training protocol Subjects in both groups trained daily, six times a week, each session consisted of $1 / 2$ hour training, for three months. The training was performed under the supervision of a physio-therapist.

Inspiratory muscle training (IMT) and Expiratory muscle training (EMT) The subjects received IMT with a threshold inspiratory muscle trainer (Threshold ${ }^{\mathrm{TM}}$ Inspiratory Muscle Trainer, Healthscan, NJ) and EMT with the same trainer held on the reversed side. Patients in group A received IMT for the first 15 minutes of each session and EMT for the last 15 minutes. The subjects started breathing at a resistance equal to $15 \%$ of their $\mathrm{PI}_{\max }$ or $\mathrm{PE}_{\max }$, for one week. The resistance was then increased incrementally, $5 \%$ each session, to reach $60 \%$ of their $\mathrm{PI}_{\max }$, or $\mathrm{PE}_{\max }$, at the end of the first month. IMT and EMT were then continued, for the next two months at this level of resistance. Patients in Group B received IMT for the whole session and followed the same protocol.

Dyspnea index The clinical rating of dyspnea was graded by a physician, who was blinded to the kind of treatment the patients have received, using the dyspnea index (Appendix A), that was based on two components evoking dyspnea: magnitude of the task which considers mainly isotonic work; and magni-

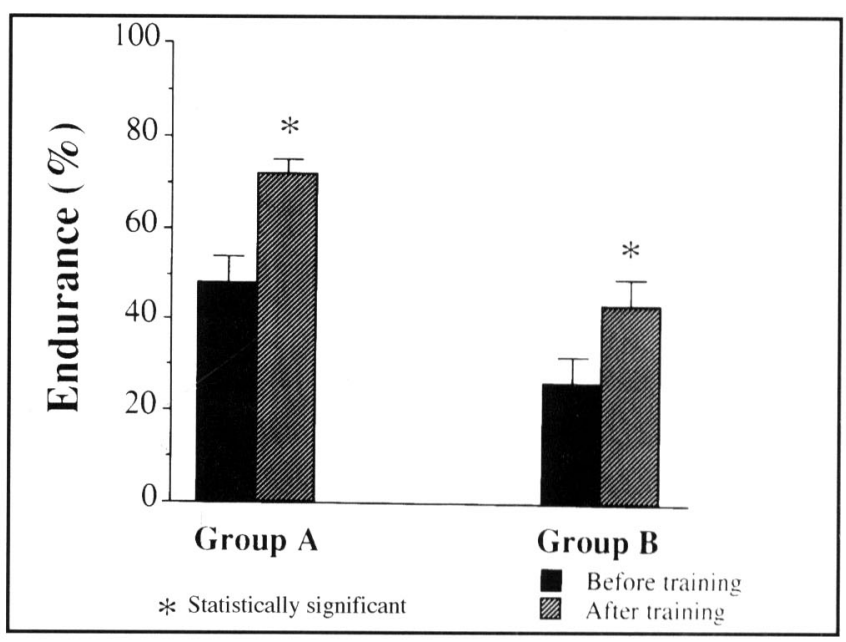

Figure 2: The respiratory muscle endurance, as expressed by the relationship between $P_{m}$ Peak and $P I_{\max }$ at baseline, and after 3 months of training, in patients with moderate (Group A) and severe (Group B) myasthenia gravis.

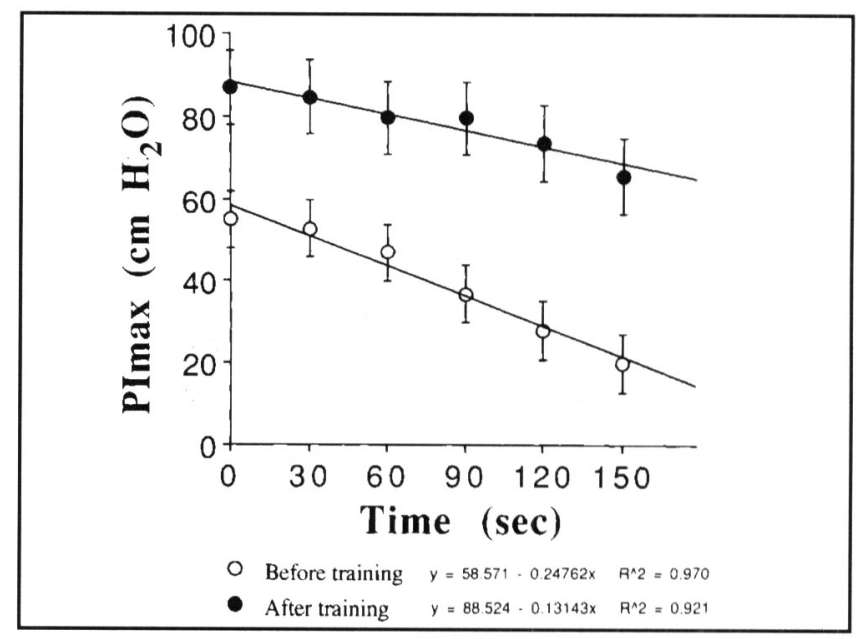

Figure 3: The dynamic inspiratory muscle strength test, as expressed by the $P I_{\max }$ at $R V$, every 30 seconds, and up to 6 measurements. The dynamic test was performed only in patients in Group $A$.

tude of effort which considers mainly isometric work. The physician selected one of five grades of dyspnea for each of the two components and the mean of the two numbers is reported. The patients in Group B all had some degree of leg and arm weakness. The physician who graded their degree of dyspnea tried to isolate this weakness from true dyspnea.

\section{Statistical analysis}

The effect of training on lung function, arterial blood gases and repiratory muscle performance was analysed using the twoway repeated measures analysis of variance (Anova). When the overall Anova was significant, post hoc comparisons were made. Chi-square (degree of freedom-1) statistics were used to compare changes in dyspnea index. Pearson correlation coefficients and linear regression analysis allowed comparison between the two regression lines in the dynamic inspiratory muscle strength test. Significance was accepted if $\mathrm{p}<0.05$. 


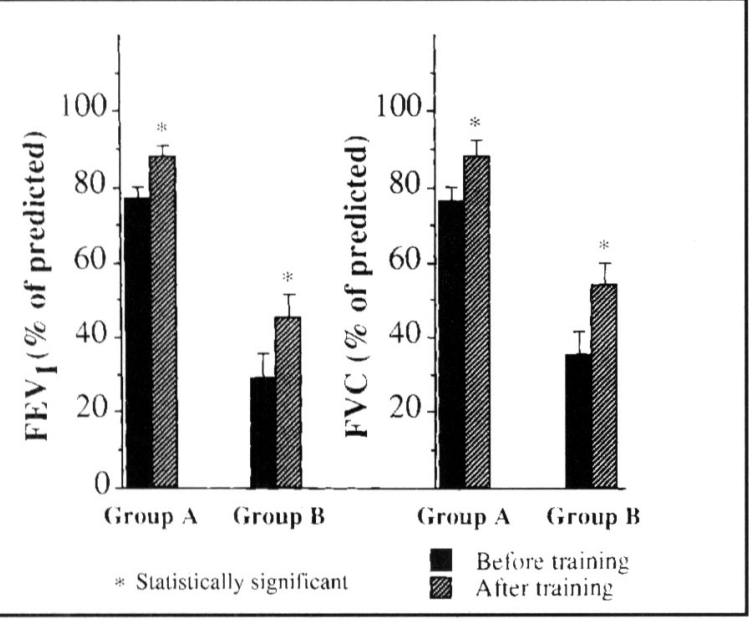

Figure 4: The effect of the training program on FEV, (left) and on the

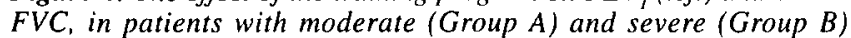
myasthenia gravis. Values are presented as \% of predicted normal values.

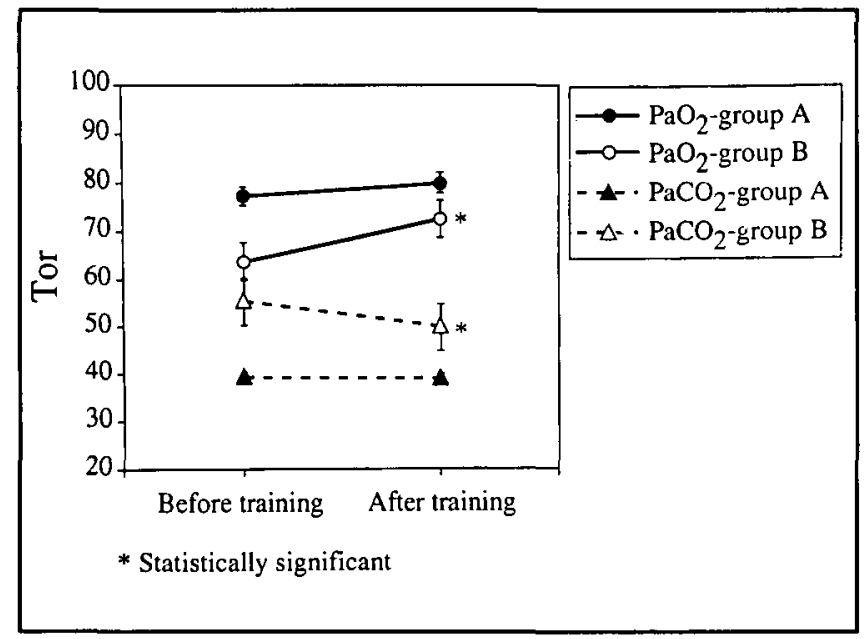

Figure 5: $\mathrm{Mean} \mathrm{PaO}_{2}$ and $\mathrm{PaCO}_{2}$ at baseline, and after 3 months of training, in patients with moderate (Group A) and severe (Group B) myasthenia gravis.

\section{RESULTS}

Respiratory muscle strength The mean effect of the training on the respiratory muscle strength is shown in Figure 1. All patients, in both Group A and Group B, showed an increase in the inspiratory muscle strength, as was assessed by measuring the $\mathrm{PI}_{\max }$ at RV. Mean $\mathrm{PI}_{\max }$ increased significantly from $56.6 \pm$ 3.9 to $87.0 \pm 5.8 \mathrm{~cm} \mathrm{H}_{2} \mathrm{O}(\mathrm{p}<0.001)$ in Group $\mathrm{A}$, and from 28.9 \pm 5.9 to $45.5 \pm 6.7 \mathrm{~cm} \mathrm{H}_{2} \mathrm{O}(\mathrm{p}<0.005)$ in Group B. The mean $\mathrm{PE}_{\max }$ also increased significantly in patients in Group $\mathrm{A}$, but remained unchanged in the patients in Group B (from $71.5 \pm 3.5$ to $86.6 \pm 4.7 \mathrm{~cm} \mathrm{H}_{2} \mathrm{O}, \mathrm{p}<0.05$, and from $28.2 \pm 2.6$ to $30.1 \pm$ $2.8 \mathrm{~cm} \mathrm{H}_{2} \mathrm{O}$, respectively).

Respiratory muscle endurance The respiratory muscle endurance, as expressed by the relationship between $\mathrm{P}_{\mathrm{m}}$ Peak and $\mathrm{PI}_{\max }\left(\mathrm{PI}_{\max }\right.$ following training) also increased significantly, from $47.9 \pm 4.0$ to $72.0 \pm 4.2 \%, p<0.001$, in patients of Group

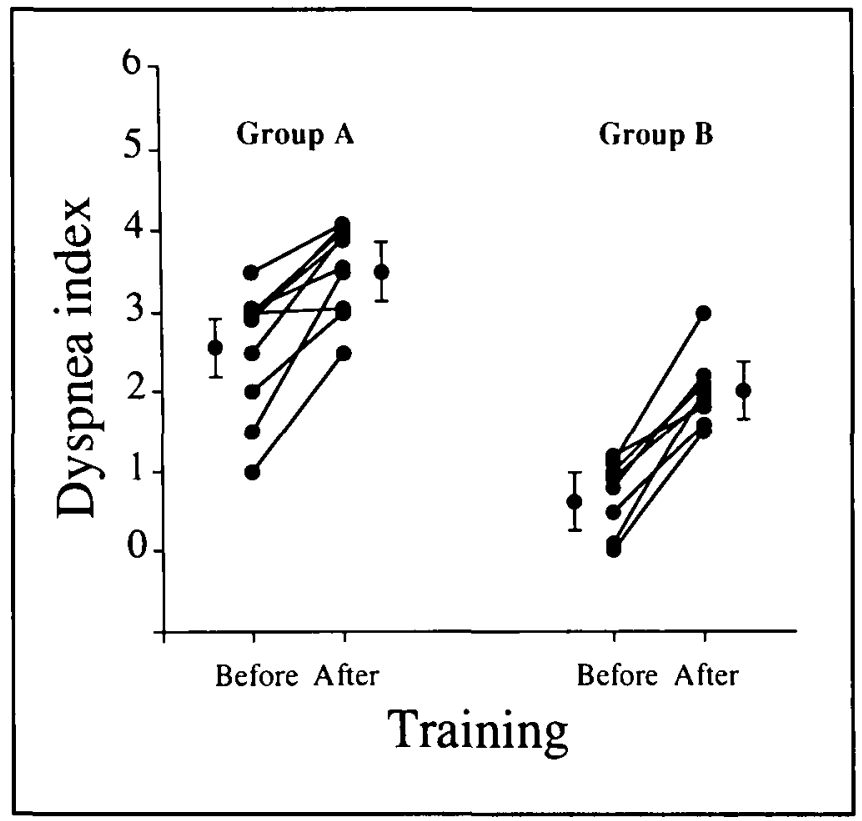

Figure 6: The effect of the training program on the individual dyspnea index score in patients with myasthenia gravis. The clinical rating of dyspnea was based on 2 components evoking dyspnea: magnitude of task, and magnitude of effort, in a scale from 0 of 4 , and the mean of the two numbers is reported.

$\mathrm{A}$, and from $26.0 \pm 2.9$ to $43.4 \pm 3.8, \mathrm{p}<0.001$, in patients in Group B (Figure 2).

Dynamic inspiratory muscle strength The dynamic inspiratory muscle strength test was performed in order to assess the progressive fatigue of the inspiratory muscles while conducting the maximal inspiratory mouth pressure maneuver 6 times with 30 seconds interval. The dynamic test was performed only in patients in Group A. It was found that not only the $\mathrm{PI}_{\max }$ was significantly improved, for every single measurement, but the decline in $\mathrm{PI}_{\max }$ that was noted for repetitive measurements, was significantly attenuated (difference between regression lines- $p$ $<0.05$ )(Figure 3).

Spirometry The effect of the training programs on lung function data are shown in Figure 4. There was a significant increase in the $\mathrm{FEV}_{1}$ values, from $77.3 \pm 2.6$ to $88.0 \pm 2.2 \%$ of predicted normal values, $\mathrm{p}<0.005$, in patients of Group $\mathrm{A}$, and from $28.9 \pm 5.9$ to $45.5 \pm 6.7, p<0.005$, in patients in Group B, and in the FVC values, from $76.2 \pm 1.8$ to $88.1 \pm 2.0, p<0.005$, in patients of Group $A$, and from $35.4 \pm 5.6$ to $53.9 \pm 5.0$, p < 0.001 , in patients in Group B.

Arterial blood gases $\mathrm{PaO}_{2}$ and $\mathrm{PaCO}_{2}$ remained almost unchanged, following training, in Group A. However, mean $\mathrm{PaO}_{2}$ increased significantly, from $63.8 \pm 3.7$ to $72.7 \pm 4.0$ Tor ( $\mathrm{p}<0.005$ ), and the mean $\mathrm{PaCO}_{2}$ decreased significantly, from $55.3 \pm 4.6$ to $49.8 \pm 3.6$ Tor $(\mathrm{p}<0.05)$ (Figure 5 ).

Dyspnea index The clinical rating of dyspnea was assessed before and after the training period. The mean dyspnea index score increased significantly from $2.6 \pm 0.8$ to $3.6 \pm 0.4(p<$ $0.005)$ in Group $A$, and from $0.7 \pm 0.2$ to $2.0 \pm 0.2(p<0.001)$ in Group B. The results of the individual dyspnea index score are shown in Figure 6. All patients but one (in Group A) improved their dyspnea index score significantly. 


\section{Discussion}

In our study, we found that specific inspiratory threshold loading training alone, or combined with specific expiratory training, 6 times a week, for $1 / 2$ hour each session, for 3 months, markedly improved respiratory muscle strength and endurance in patients with MG. This improvement in respiratory muscle performance was associated with improved lung function and decreased dyspnea. Our findings are weakened by the lack of a control group. However, the number of patients that could be recruited for the study was limited, and we preferred to have a significant number of patients in the training group, instead of randomizing them between a study group and a control group.

Respiratory muscle performance is reduced in MG. MierJedrzejowicz and associates ${ }^{6}$ have already demonstrated, in a study of 17 patients with MG, that the mean $\mathrm{PI}_{\max }$ was $52 \%$ and the mean $\mathrm{PE}_{\max }$ was $54 \%$ of predicted normal values. In addition, $\mathrm{PI}_{\max }$ and $\mathrm{PE}_{\max }$ significantly improved following the administration of an anticholinesterase agent, suggesting that the reduced strength of the respiratory muscles was due to MG.

The weakness of the respiratory muscles in patients with MG is usually symptomatic, depending on the severity of the disease. It may vary from dyspnea only with a vigorous effort to dyspnea that is apparent at rest. ${ }^{9}$ A number of studies have been carried out in order to correlate dyspnea and respiratory muscle performance. It was well documented that the intensity of breathlessness is related to the activity and the strength of the inspiratory muscles.$^{28}$ In patients with MG, VC is usually low due to reduced inspiratory capacity and expiratory reserve volume. The reduction of lung volume may lead to patchy areas of atelectasis and consequently to ventilation-perfusion mismatch and hypoxemia. Hypercapnia may also occur as a result of hypoventilation secondary to fatigue of the inspiratory muscles. Hypoxemia, with or without hypercapnea, may lead to increased work of breathing. In addition, previous reports suggest that patients with MG may have reduced pulmonary ${ }^{29}$ and chest wall ${ }^{30}$ compliance, which by itself increases the work of breathing. Their increased work combined with impaired respiratory muscle function accounts for the patients' sense of dyspnea. Therefore, specific respiratory muscle training seems to play an important role in the management of patients with MG, as an addition to common acceptable medical therapy. If dyspnea is related to the increased work, combined with impaired function of the respiratory muscles, then improved strength and endurance of those muscles must be followed by improvment in symptoms.

The majority of patients treated with anticholinesterase will improve significantly. ${ }^{12}$ However, most of them will remain with impaired respiratory muscle perfomance and will continue to deteriorate. In addition, overdosage with anticholinesterase treatment may result in increased muscle weakness. Corticosteroids may also improve symptoms in patients with MG; however, there is always the risk of exacerbating muscle weakness, because of myopathic effects. ${ }^{3 !}$

Patients with MG, not only may have variable degree of dyspnea, but may exhibit respiratory failure either spontaneously or secondary to intercurrent infection, emotional trauma, surgery (especially after thymectomy) or other complications. ${ }^{32}$ Improved strength and endurance of the inspiratory muscles may also delay the onset of respiratory muscle fatigue and respiratory failure in those patients.

Leith and Bradley, ${ }^{16}$ were the first to report that respiratory muscle can be specifically trained in normal persons. Later,

\section{APpendix A}

\section{Dyspea index}

\section{Magnitude of task}

Grade 4

Extraordinary. Becomes short of breath only with extraordinary activity, such as carrying very heavy loads on the level, lighter loads uphill, or running. No shortness of breath with ordinary task.

Grade 3 Major. Becomes short of breath only with such major activities as walking up a steep hill, climbing more than three flights of stairs, or carrying a moderate load on the level.

Grade 2 Moderate. Becomes short of breath with moderate or average tasks, such as walking up a gradual hill, climbing less than three flights of stairs, or carrying a light load on the level.

Grade 1 Light. Becomes short of breath with activities, such as walking on the level, washing, standing or shopping.

Grade 0 No task. Becomes short of breath at rest, while sitting, or lying down.

\section{Magnitude of effort}

Extraordinary. Becomes short of breath only with the greatest imaginable effort. No shortness of breath with ordinary effort.

Major. Becomes short of breath with effort distinctly submaximal, but of major proportion. Tasks performed without pause unless the task requires extraordinary effort that may be performed without pause.

Moderate. Becomes short of breath with moderate effort. Tasks performed with occasional pause and requiring longer to complete than the average person.

Light. Becomes short of breath with little effort.

No effort. Becomes short of breath at rest, while sitting, or lying down. 
Gross and coworkers ${ }^{17}$ showed that resistive breathing training improves inspiratory muscle function in quadriplegics. Since then, many reports have shown the efficacy of inspiratory muscle training in patients with different pulmonary diseases. ${ }^{13-15,18-22}$ However, IMT or EMT have only been tried in a small group of patients with MG. Our study shows that respiratory muscle training can be performed in patients with MG with significant improvement of respiratory muscle performance, and a reduction in the sense of dyspnea. It may also prevent or delay the need for mechanical ventilation. From this study we can not conclude whether the addition of EMT to IMT is associated with any further improvement. The combination of EMT and IMT was applied only in patients with less severe disease (Group A), while in the patients with more severe disease we tried to reduce the load of training by eliminating the EMT. Nevertheless, both groups improved almost the same amount. Further studies are needed to answer that question.

One may wonder whether the improvement of $\mathrm{PI}_{\max }$ and $\mathrm{PE}_{\max }$ was due to changes in lung volume and not due to true improvement in the performance of the respiratory muscles. Although residual volume could be decreased following training, the magnitude of the improvement in the respiratory muscle performance was much too high to relate it only to lung volume changes. In addition, measurements of respiratory muscle performance are all dependent on the patient's motivation. Therefore, all patients were trained, to get familiar with the measurements, and highly motivated before entering the study, and baseline results were considered only after obtaining the best values in 3 consecutive measurements. We are almost convinced that the increase in these measurements represents true improvement and not just a motivational effect.

In conclusion, we believe that IMT alone or in combination with EMT may provide a complementary and more physiologic therapy, with the aim of reducing dyspnea symptoms in patients with MG. It may also prevent or delay the breathing crisis and the need for mechanical ventilation that is associated with the disease.

\section{REFERENCES}

1. Drachman DB. Myasthenia gravis. N Engl J Med 1978; 298: 136142.

2. Lindstrom JM, Seybold ME, Lennon VA. Antibody to acetylcholine receptor in myasthenia gravis. Neurology 1976; 26: 1054-1059.

3. Seybold ME. Myasthenia gravis. A clinical and basic review. JAMA 1983; 250: 2516-2523.

4. Kelly BJ, Luce JM. The diagnosis and management of neuromuscular diseases causing respiratory failure. Chest 1971; 99: 14851494.

5. Ringqvist I, Ringqvist T. Respiratory mechanics in untreated myasthenia gravis with special reference to the respiratory forces. Acta Med Scand 1971; 190: 499-508.

6. Mier-Jedrzejowicz AK, Brophy C, Green M. Respiratory muscle function in myasthenia gravis. Am Rev Respir Dis 1988; 138 : 867-873.

7. Newsom DJ, Loh L. Alveolar hypoventilation and respiratory muscle weakness. Bull Eur Physiopathol Respir 1979; 15: 45-51.

8. Ferguson PT, Murphy RP, Lascelles RG. Ventilatory failure in myasthenia gravis. J Neurol Neurosurg Psychiatry 1982; 45: 217-222.
9. Zulueta JJ, Fanburg BL. Respiratory dysfunction in myasthenia gravis. Chest 1994; 15: 683-691.

10. Buckingham JM, Howard FM, Bernatz PE. The value of thymectomy in myasthenia gravis: a computer assisted matched study. Ann Surg 1975; 184: 453-459.

11. Pascuzzi RM, Coslett HB, Johns TR. Long term corticosteroid treatment of myasthenia gravis: report of 116 patients. Ann Neurol 1984; 15: 291-298.

12. Drachman DB. Myasthenia gravis. In: Wilson JD, Braunwald E, Isselbacher KJ, et al., eds. Principles of Internal Medicine, 12th Edn, New York: McGraw-Hill, 1991; 2118.

13. Pardy RL, Leith DE. Ventilatory muscle training. Resp Care 1984; 29: 278-284.

14. Shaffer TH, Wolfson MR, Bhutani VK. Respiratory muscle function, assessment, and training. Physical Therapy 1981; 61(12): 1711-1723.

15. Pardy RL, Leith DE. Ventilatory muscle training. In: Rousos and Mackelm, eds. "The Thorax", New York: Marcel Dekker, Inc.; P1353-1369.

16. Leith DE, Bradley $M$. Ventilatory muscle strength and endurance training. J Appl Physiol 1976; 41: 508-516.

17. Gross D, Ladd HW, Riley E, Macklem P, Grassino A. The effect of training on strength and endurance of the diaphragm in quadriplegia. Am J Med 1980; 68: 27-35.

18. Weiner P, Azgad Y, Ganam R, Weiner M. Inspiratory muscle training in patients with bronchial asthma. Chest 1992; 102: 13571361.

19. Weiner P, Ganam R., Zamir D, Zonder C. Specific inspiratory muscle training in patients with end stage renal failure. "Harefuah" $\mathrm{J}$ Israel Medi Assoc 1996; 130(2): 1-4.

20. Weiner P, Zeidan F, Zamir D, Pelled B. Prophylactic inspiratory muscles training before CABG. "Harefuah" J Israel Med Assoc 1995; 129(7-8): 225-228.

21. Gross D, Appelbaum A. Respiratory muscle training in health and disease. In: Grassino A, et al., eds. "Current Topics in Rehabilitation-Chronic Pulmonary hyperinflation", London: Saunders. 1991; 159-168.

22. Pardy RL, Rivington RN, Despas PJ, Macklem PT. The effects of inspiratory muscle training on exercise performance in chronic airflow limitation. Am Rev Respir Dis 1981; 123: 426-433.

23. Gross $D$, Meiner $Z$. The effect of ventilatory muscle training on respiratory function and capacity in ambulatory and bed ridden patients with neuromuscular disease. Monaldi Arch Chest Dis 1993; 48: 322-326.

24. Osserman K. Myasthenia Gravis. New York: Grune and Stratton, 1958.

25. Black LF, Hyatt RE. Maximal respiratory pressures: normal values and relationship to age and sex. Am Rev Respir Dis 1969; 99: 696-702.

26. Nickerson BG, Keens TG. Measuring ventilatory muscle endurance in humans as sustainable inspiratory pressure. J Appl Physiol 1982; 52: 768-772.

27. Martyn JB, Moreno RH, Pare PD, Pardy RL. Measurement of inspiratory muscle performance with incremental threshold loading. Am Rev Respir Dis 1987; 135: 919-923.

28. Killian KJ, Gandevia SC, Summers E. Effect of increased lung volume on perception of breathlessness, effort, and tension. J Appl Physiol 1984; 57: 686-691.

29. Gibson GJ, Pride NB, Newson Davis J, Loh LC. Pulmonary mechanics in patients with respiratory muscle weakness. Am Rev Respir Dis 1977; 115: 389-395.

30. Estenne M, Heilporn A, Delhez L, Yernault J, De Troyer A. Chest wall stiffness in patients with chronic respiratory muscle weakness. Am Rev Respir Dis 1983; 128: 1002-1007.

31. Weiner P, Azgad Y, Weiner M. The effect of corticosteroids on inspiratory muscle performance in humans. Chest 1993; 104: 1788-1791.

32. Gracey DR, Divertie MB, Howard FM. Mechanical ventilation for respiratory failure in myasthenia gravis: two year experience with 22 patients. Mayo Clin Proc 1983; 58: 597-601. 